\title{
Independent control of metal cluster and ceramic particle characteristics during one-step synthesis of $\mathrm{Pt} / \mathrm{TiO}_{2}$
}

\author{
Heiko Schulz, Lutz Mädler, Reto Strobel, Rainer Jossen, and Sotiris E. Pratsinis ${ }^{\text {a) }}$ \\ Particle Technology Laboratory, Institute of Process Engineering, Department of Mechanical and \\ Process Engineering, ETH Zürich, CH-8092 Zürich, Switzerland \\ Tue Johannessen \\ Interdisciplinary Research Center for Catalysis, Department of Chemical Engineering, \\ Technical University of Denmark, DK-2800 Lyngby, Denmark
}

(Received 28 April 2005; accepted 22 June 2005)

\begin{abstract}
Rapid quenching during flame spray synthesis of $\mathrm{Pt} / \mathrm{TiO}_{2}(0-10 \mathrm{wt} \% \mathrm{Pt})$ is demonstrated as a versatile method for independent control of support $\left(\mathrm{TiO}_{2}\right)$ and noble metal $(\mathrm{Pt})$ cluster characteristics. Titania grain size, morphology, crystal phase structure, and crystal size were analyzed by nitrogen adsorption, electron microscopy and $\mathrm{x}$-ray diffraction, respectively, while Pt-dispersion and size were determined by CO-pulse chemisorption. The influence of quench cooling on the flame temperature was analyzed by Fourier transform infrared spectroscopy. Increasing the quench flow rate reduced the Pt diameter asymptotically. Optimal quenching with respect to maximum Pt-dispersion ( $60 \%)$ resulted in average Pt diameters of 1.7 to $2.3 \mathrm{~nm}$ for Pt-contents of 1-10 wt $\%$, respectively.
\end{abstract}

\section{INTRODUCTION}

Noble metals dispersed on ceramic particles are important in sensors, electronics, and most notably in catalysis. The size of the noble metal cluster has a profound influence on the material performance, e.g., for structure sensitive reactions ${ }^{1}$ and sensor sensitivity. ${ }^{2}$ Though typically these materials are made by multi-step wetchemistry processes, recently, flame technology has been used for one-step synthesis of $\mathrm{Pt}, \mathrm{Pd}, \mathrm{Ag}$, and $\mathrm{Au}$ nanoparticles on various nanostructured supports such as $\mathrm{Al}_{2} \mathrm{O}_{3},{ }^{3,4} \mathrm{SiO}_{2},{ }^{5}$ and $\mathrm{TiO}_{2} .{ }^{5-7}$ The as-prepared materials exhibit a high external specific surface area $\left(40-320 \mathrm{~m}^{2} /\right.$ g) with a high degree of crystallinity and an excellent noble metal dispersion. The large external surface area makes them attractive for mass transfer limited reactions such as in chiral catalysts ${ }^{3}$ and high-temperature applications. The addition of noble metals does not usually influence the ceramic support characteristics as metal precipitation follows that of the ceramic support. ${ }^{5}$ Until now, the flame-made noble metal cluster size could be controlled only by its initial precursor concentration at constant production conditions. ${ }^{5}$ At a given noble metal concentration, the support and noble metal particle sizes change concurrently by varying the process parameters

\footnotetext{
a) Address all correspondence to this author.

e-mail: pratsinis@ptl.mavt.ethz.ch

DOI: $10.1557 / J M R .2005 .0319$
}

(e.g., flame enthalpy content through the oxidant or fuel composition). ${ }^{4}$ Therefore, decoupling the noble metal cluster size control from that of the ceramic support has been a challenge in one step flame synthesis of mixed metal-ceramic particles.

This can be achieved by manipulation of flame cooling during particle formation. Unagglomerated silica ${ }^{8}$ and titania ${ }^{9}$ particles with reduced primary particle sizes can be made by increasing the cooling rate through increasing the oxidant flow. External electrical fields to the flame induce ionic winds that increase flame cooling and reduce product primary particles. ${ }^{10,11}$ Quenching the entire flame through a critical flow nozzle can also rapidly reduce the flame temperature resulting in nonagglomerated particles and even titania suboxides. ${ }^{12}$ Another possibility for controlled quench cooling is the direct radial injection of cold air from a quench ring into a vapor-fed flame at a given height. ${ }^{13}$ The specially arranged nozzles create a swirl-stabilized upward flow with limited disturbance upstream of the quenching ring and introduce additional oxygen into the flame ensuring complete oxidation of the precursor and simultaneously decreased the product primary particle size. Radial quench cooling has-apart from the original study on quench cooling of vapor-fed flame synthesis ${ }^{13}$-been demonstrated for flame spray synthesis of pure $\mathrm{TiO}_{2}{ }^{14}$

Here, the application of radial quench cooling method is explored for decoupling the metal dispersion from the 
ceramic particle size during $\mathrm{Pt} / \mathrm{TiO}_{2}$ synthesis by the highly versatile flame spray pyrolysis process. The Pt/ $\mathrm{TiO}_{2}$ is selected for its broad application in catalysis such as photocatalytic ${ }^{15}$ and hydrogenation reactions ${ }^{16}$ and the relatively simple crystallinity of $\mathrm{TiO}_{2}$ compared to other supports such as $\mathrm{Al}_{2} \mathrm{O}_{3}$. The role of the quenching location on the particle characteristics of $\mathrm{Pt} / \mathrm{TiO}_{2}$ is investigated systematically at constant flame enthalpy content, titanium concentration, dispersion gas flow, and solvent composition but variable quench gas flow and platinum content.

\section{EXPERIMENTAL}

\section{A. Precursor preparation and flame synthesis}

Powders were produced in a laboratory-scale spray flame reactor (Fig. 1). ${ }^{17} \mathrm{~A}$ concentric two-phase nozzle (capillary inner/outer diameter $0.41 / 0.72 \mathrm{~mm}$ ) and annulus (outer diameter $0.97 \mathrm{~mm}$ ) was used to spray the metal-containing liquid mixture. The annular gap area of the dispersion gas $\left(\mathrm{O}_{2}\right.$, Pan Gas, $99.95 \%$, Luzern, Switzerland) was adjusted to achieve a 1.5 bar pressure drop at the nozzle. In all experiments, a syringe pump (Inotec, RS 232, Oberwinterthur, Switzerland) fed $5 \mathrm{ml} / \mathrm{min}$ of the precursor solution into the flame through the innermost
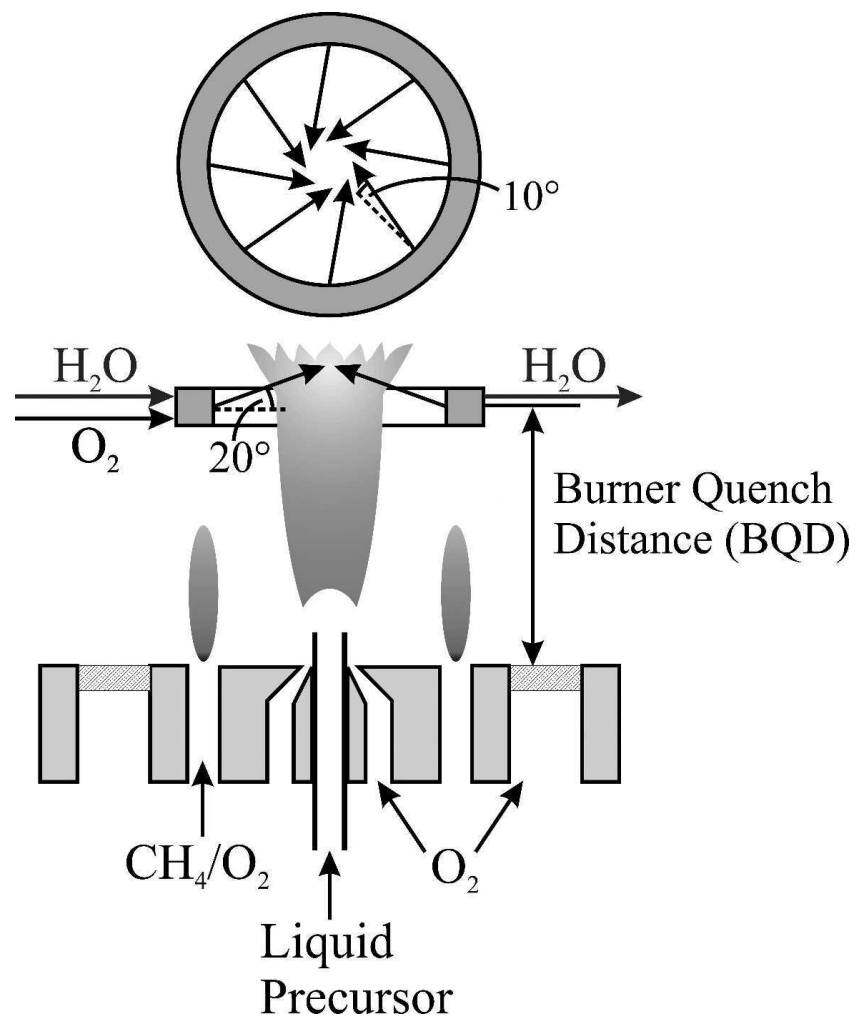

FIG. 1. Burner with quench cooling device. The water-cooled quench ring injects cooling gas from eight almost vertical nozzles, specifically directed to give an upward-directed, swirling flow with intimate mixing with the hot product gas of the flame. Its distance between the burner nozzle and quench ring (BQD) was adjusted from 2 to $12 \mathrm{~cm}$. capillary, where it was dispersed into fine droplets by $5 \mathrm{l} / \mathrm{min} \mathrm{O}_{2}$ flowing from the first annulus. The spray was ignited by a circular premixed flame (inner diameter $6 \mathrm{~mm}$, slit width $10 \mu \mathrm{m})$ of $\mathrm{CH}_{4}(1.5 \mathrm{l} / \mathrm{min}$, Pan Gas, $99.5 \%$, Luzern, Switzerland) and $\mathrm{O}_{2}(3.2 \mathrm{l} / \mathrm{min})$. An additional $\mathrm{O}_{2}$ sheath $(5 \mathrm{l} / \mathrm{min})$ was supplied through a ring of sinter metal (inner/outer diameter $18 / 34 \mathrm{~mm}$ ). All gas flow rates were controlled by calibrated mass flow controllers (Bronkhorst, Ruurlo, The Netherlands). The production rate of pure $\mathrm{TiO}_{2}$ was $15.6 \mathrm{~g} / \mathrm{h}$, while when adding $10 \mathrm{wt} \%$ platinum this increased to $17.2 \mathrm{~g} / \mathrm{h}$.

Titanium iso-propoxide (Aldrich, 97\%, Buchs, Switzerland) and platinum (II) acetyl-acetonate (Strem Chemicals, 98\%, Kehl, Germany) were used as titanium and platinum precursors, respectively. Appropriate amounts of the precursors were diluted and dissolved in a 11:5 (by volume) mixture of xylene (Fluka, $>98.5 \%$, Buchs, Switzerland) and acetonitrile (Fluka, >99.5\%). The Ti concentration was kept constant $(0.67 \mathrm{M})$ for all experiments. The nominal Pt-weight fraction ranged from 0 to 10 .

The combustion enthalpy density $\left(\mathrm{kJ} / \mathrm{g}_{\text {gas }}\right)$ was calculated from the ratio of the specific combustion enthalpy $\left(\mathrm{kJ} / \mathrm{ml}_{\text {liquid }}\right)$ of the reactants and by the specific mass $\left(\mathrm{g}_{\mathrm{gas}} / \mathrm{ml}_{\text {liquid }}\right)$ of the evolving gases at complete combustion conditions (products: $\mathrm{CO}_{2}, \mathrm{H}_{2} \mathrm{O}, \mathrm{TiO}_{2}$, and Pt). ${ }^{18}$ All experiments were carried out at a constant combustion enthalpy density of $9.1 \mathrm{~kJ} / \mathrm{g}_{\text {gas }}$, neglecting the additional quench gas flow.

A 2-cm-long water-cooled quench ring (inner/outer diameter $41 / 51 \mathrm{~mm}$ ) with eight evenly distributed gas outlets in its inner annulus (diameter $1 \mathrm{~mm}$ each) was placed axially downstream from the nozzle (Fig. 1). ${ }^{13}$ Quench gas with a total flow rate ranging from 0 to $50 \mathrm{l} / \mathrm{min}$ was injected radially into the flame spray, though most of the experiments were carried out at $40 \mathrm{l} / \mathrm{min}$ unless otherwise noted. As in the original design, ${ }^{13}$ the gas outlet nozzles of the quench ring are directed $10^{\circ}$ away from the center line of the ring and pointing downstream by $20^{\circ}$ to reduce upstream flame distortions (Fig. 1, inset). This is essential to enable well defined studies of the influence of quench cooling on the product properties without disturbing the entire flame zone. The ring was internally cooled by flowing $0.83 \mathrm{l} / \mathrm{min}$ water $\left(7^{\circ} \mathrm{C}\right)$. The quench ring distance above the burnernozzle (BQD) was varied from 2 to $12 \mathrm{~cm}$. The product powders were collected by a vacuum pump (Busch SV 1025 B, Magden, Switzerland) on a glass microfibre filter (Whatman GF/D, Springfield Mill, UK, $25.7 \mathrm{~cm}$ in diameter).

\section{B. Temperature measurements and particle characterization}

The gas temperature in the spray flame was measured by non-intrusive Fourier transform infrared (FTIR) 
emission/transmission spectroscopy. ${ }^{19}$ The spectrometer (Bomem Inc., Quebec, Canada Model MB157) operated over a spectral range of 6500 to $500 \mathrm{~cm}^{-1}$ with a resolution of $2 \mathrm{~cm}^{-1}$ and $4 \mathrm{~mm}$ infrared (IR) beam. ${ }^{20}$ Transmission and emission (radiance) spectra were collected with a mercury-cadmium-tell (MCT) detector. The zero position above the burner was set, when half of the signal was blocked by the burner nozzle. Path correction spectra for the emission measurements were taken with a black body cavity in place of the burner nozzle. The background spectrum for transmission was taken with oxygen (dispersion, flamelet, and sheath) flowing but without the presence of $\mathrm{CH}_{4}$ and spray droplets. The spray flames were measured by 512 scans for one transmission and emission spectra, respectively, which were radiancecorrected. ${ }^{20}$ Average flame temperatures were estimated using the emission/transmission and the normalized radiance procedures for hot $\mathrm{CO}_{2} \cdot{ }^{19}$ The temperatures shown here were averages from both procedures representing the average flame temperature in the line of sight through the center of the flame. ${ }^{20}$ For validation of the spray flame temperatures, measurements at some heights were carried out three times.

High-resolution transmission electron microscope (HRTEM) images and electron diffraction x-ray (EDX) pattern were taken with a CM30ST microscope (Philips, Eindhoven, The Netherlands, LaB6 Cathode, 300kV, point resolution $0.2 \mathrm{~nm}$ ). Particles were disposed onto a carbon foil supported on a copper grid. A high-angle annular dark field (HAADF) detector was used for scanning transmission electron microscopy (STEM). Specific surface areas $\left(\mathrm{SSA}, \mathrm{m}^{2} / \mathrm{g}\right)$ of the materials were determined from the adsorption of nitrogen at $77 \mathrm{~K}$ using the Brunauer-Emmett-Teller method (Micromeritics Tristar 3000, Brussels, Belgium, 5-point isotherm, $0.05<p / p_{0}<$ 0.25). A Bruker D 8 Advance diffractometer was used for $\mathrm{X}$-ray diffraction (XRD; $\mathrm{Cu} \mathrm{K}$ radiation, step size $0.03^{\circ}$, scan speed $0.60^{\circ} \mathrm{min}^{-1}$ ) measurements. For determination of the anatase and rutile crystal size, XRD pattern were fitted by TOPAS 2 (Bruker AXS) with the Rietveld method $^{21,22}$ from $2 \theta=21^{\circ}$ to $31^{\circ}$ covering the most intensive signals of both crystal structures using a linear background. $^{5}$

Platinum dispersion was determined by CO-pulse chemisorption (Micromeritics Autochem II 2920, Brussels, Belgium). Prior to each measurement the samples were reduced in $\mathrm{H}_{2}(20 \mathrm{ml} / \mathrm{min})$ at $300{ }^{\circ} \mathrm{C}$ for $0.5 \mathrm{~h}$ and then flushed with $\mathrm{He}(20 \mathrm{ml} / \mathrm{min})$ at $300{ }^{\circ} \mathrm{C}$ for $1.5 \mathrm{~h}^{23}$ Carbon monoxide (10\% in $\mathrm{He}, 0.5 \mathrm{ml}$ ) was pulsed into a He flow $(50 \mathrm{ml} / \mathrm{min})$ at $45{ }^{\circ} \mathrm{C}$ while its concentration was monitored by a TCD detector. For calculating the Ptdispersion an adsorption stoichiometry of $\mathrm{Pt} / \mathrm{CO}=1$ was assumed. ${ }^{24}$ The amount of residual carbon in the powder was determined (Micromeritics Autochem II $2920)$ by heating the particles in $\mathrm{O}_{2}\left(20 \mathrm{ml} \mathrm{min}^{-1}\right.$, Pan
Gas, $99.999 \%$ ) up to $900{ }^{\circ} \mathrm{C}$ with $10{ }^{\circ} \mathrm{C} \mathrm{min}^{-1}$ and monitoring the evolving $\mathrm{CO}_{2}$ and $\mathrm{CO}$ with a mass spectrometer (ThermoStar, Asslar, Germany, Pfeiffer Vacuum). The mass spectrometer signal arising from $\mathrm{CO}$ was hardly above the noise level, so that only the signal corresponding to $\mathrm{CO}_{2}$ was taken account for determination of the carbon content. Subsequent to each experiment a pulse of $1.56 \times 10^{-5} \mathrm{~mol} \mathrm{CO}_{2}$ (Pan Gas, 99.9\%) was measured for calibration.

\section{RESULTS AND DISCUSSION}

\section{A. Spray flame characterization}

Nanostructured $\mathrm{Pt} / \mathrm{TiO}_{2}$ particles containing $0-10 \mathrm{wt} \%$ Pt were produced by combustion of the appropriate precursor solutions without the quench ring (unquenched flame) and with it injecting $40 \mathrm{l} / \mathrm{min}$ (unless otherwise stated) at various burner-quench-ring distances (BQD, quenched flame). Figure 2 shows the axial temperature profiles of the pure $\mathrm{TiO}_{2}$ producing unquenched (squares) and quenched spray flame at $\mathrm{BQD}=6 \mathrm{~cm}$ (circles). The temperature profile of the flamelets (triangles) that ignite and sustain spray combustion (without the ignited spray) is also shown in Fig. 2. The maximum flamelet temperature was $2000{ }^{\circ} \mathrm{C}$ close to the burner but dropped drastically above $0.6 \mathrm{~cm}$ to approximately $500{ }^{\circ} \mathrm{C}$ at $4 \mathrm{~cm}$ by mixing with the surrounding gas. ${ }^{25} \mathrm{In}$ contrast, the maximum spray flame temperature was $2300{ }^{\circ} \mathrm{C}$ up to a height of $5 \mathrm{~cm}$. Droplets containing solvent and precursor continuously evaporate and supply

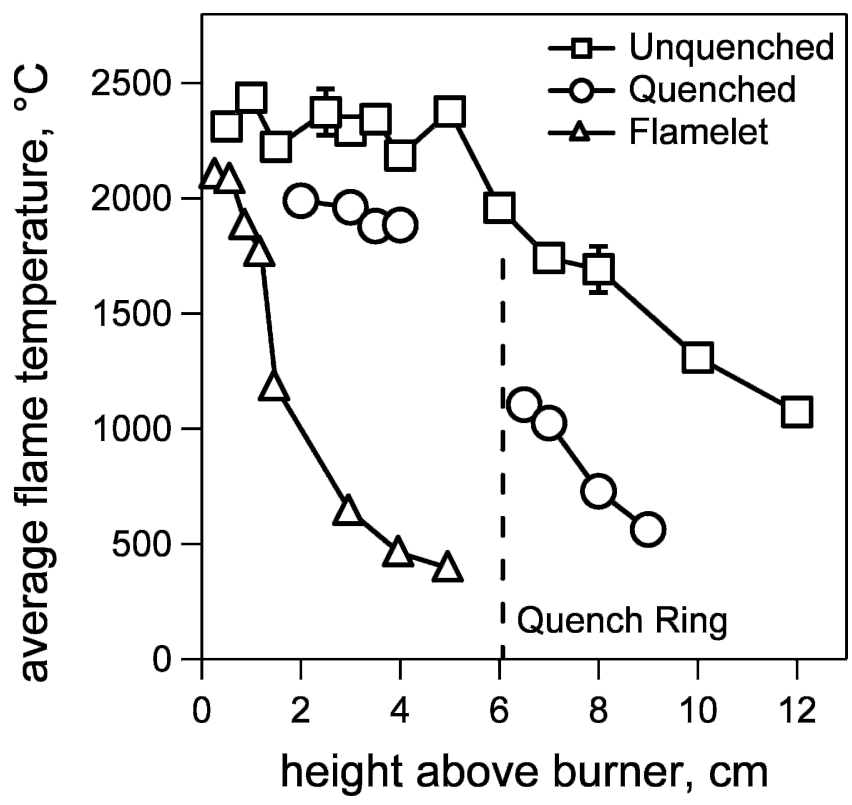

FIG. 2. Temperature profiles of the flame spray at standard conditions (squares), with quench ring installed at $6 \mathrm{~cm}$ (circles, $40 \mathrm{l} / \mathrm{min}$ ), and without precursor feed (triangles). The quenched flame showed a constant temperature region of $2000{ }^{\circ} \mathrm{C}$ upstream of the quench ring, whereas downstream, the temperature was about $800-1000{ }^{\circ} \mathrm{C}$ lower than for the unquenched flame. 
the fuel for combustion resulting in a rather constant temperature up to about $5 \mathrm{~cm}$ (Fig. 2, squares). This evaporation region is observed also in classic fuel spray combustion. ${ }^{25}$ It is attributed to fuel mass transfer limitation that slows the combustion and prolongs the high temperature region. The distinctive constant temperature region can be shortened, for example, by increasing the oxidant flow. This dilutes the fuel accelerating mass transfer and results in earlier maximum flame temperatures and faster cooling rates. ${ }^{8,17}$ After droplet evaporation and fuel (solvent) combustion, the flame temperature decreases similar to gas-fed flames. ${ }^{10}$

The applied line-of-sight FTIR analysis averages the $\mathrm{CO}_{2}$ temperatures throughout the spray flame. In contrast, spatially resolved flame temperature profiles can be obtained by tomographic reconstruction of radial resolved line-of-sight FTIR measurements, as demonstrated for a premixed gas-fed flame reactor. ${ }^{20}$ It was shown that FTIR analysis gives temperatures slightly lower than the ones obtained by coherent anti-Stokes Raman scattering at the centerline of the flame. In the case of the presented spray flame, the maximum flame width of approximately $3 \mathrm{~cm}$ was too small for tomographic reconstruction with a 4-mm IR beam. It should be noted that radial temperatures in spray flames can differ up to $800{ }^{\circ} \mathrm{C} .{ }^{26}$ Steep temperature gradients are especially observed at low heights above the burner, where the centerline temperature is lowered because of evaporating droplets, resulting in the highest temperatures slightly off center.

Quenching the flame at BQD $=6 \mathrm{~cm}$ (Fig. 2, circles) lowered the flame temperature by $300{ }^{\circ} \mathrm{C}$ upstream of the quench ring $(2-4 \mathrm{~cm})$ and by $800-1000{ }^{\circ} \mathrm{C}$ downstream. The high momentum of the cooling jets, which flow in a distinct, upwards-swirling pattern, entrain cold gas into the flame upstream (below) of the ring as it has been seen also with vapor-fed flames quenched by a critical flow nozzle, ${ }^{12}$ which also resulted in a temperature reduction upstream of the quenching device. Originally, the radial quench cooling method was developed for a flame synthesis unit with evaporated metal precursor fed as a gas jet to a flat premixed flame. ${ }^{13}$ In that system, no differences in temperature profile (with/without quench cooling) was observed below the quenching level as this particular flame setup had been operated with a quartz chimney surrounding in the flame reaction zone, and no external air could be withdrawn into the flame zone.

After the injection of quench gas (BQD $=6 \mathrm{~cm}$ ), the flame temperature was $1000{ }^{\circ} \mathrm{C}$ at $6.5 \mathrm{~cm}$, resulting in a cooling rate of $310 \mathrm{~K} / \mathrm{cm}$. Without quenching, the flame temperature drops at $1000{ }^{\circ} \mathrm{C}$ much further downstream at approximately $12 \mathrm{~cm}$ above the burner with a cooling rate of $170 \mathrm{~K} / \mathrm{cm}$. Thus, using the quench ring decreases substantially the high temperature residence time of the particle.

\section{B. $\mathrm{TiO}_{2}$ particle characterization}

Figure 3 shows the influence of the BQD on the SSA of both pure (squares) and $5 \mathrm{wt} \% \mathrm{Pt}$-containing $\mathrm{TiO}_{2}$ (circles). Figure 3 also shows a transmission electron microscope (TEM) image of pure, solid $\mathrm{TiO}_{2}$ particles made (left) without and (right) with the quench ring at $6 \mathrm{~cm}$ BQD. The particles have a homogeneous morphology and rather spherical shape for both conditions. ${ }^{5}$ The highly crystalline structure of the $\mathrm{TiO}_{2}$ particles was corroborated by the intense electron diffraction pattern (Fig. 3, TEM insets). Only a few necks from sintering could be observed, indicating mostly nonagglomerate particles. Quenching the flame at $6 \mathrm{~cm}$ had no significant influence on the morphology, crystallinity, and size of the $\mathrm{TiO}_{2}$ particles. All powders exhibited high SSAs, above $76 \mathrm{~m}^{2} / \mathrm{g}$. Quenching at $8 \mathrm{~cm}$ or larger BQDs did not affect the SSA significantly compared to the unquenched flame $(\mathrm{BQD}=\infty)$. Lowering the quench ring from 8 to $4 \mathrm{~cm}$ increased the SSA as shortened residence times in the hot temperature zone resulted in smaller primary particles. It should be noted that the dependence of the SSA as a function of BQD is dramatically different from that of vapor-fed flames quenched by a critical flow nozzle. For small BQDs below $4 \mathrm{~cm}$, the SSA of pure $\mathrm{TiO}_{2}$ decreased from a maximum of 138 to $120 \mathrm{~m}^{2} / \mathrm{g}$. Quenching may have extinguished the spray flame prematurely. In fact, as Fig. 2 shows at positions lower

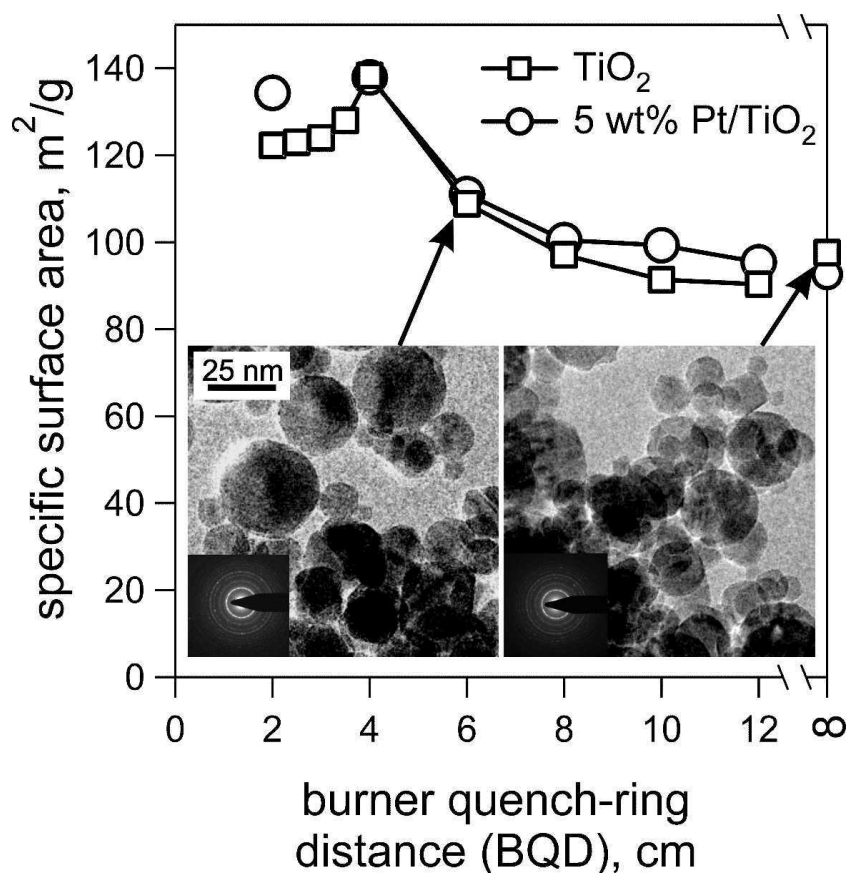

FIG. 3. Influence of the BQD (40 1/min) on the SSA of pure (squares) and $5 \mathrm{wt} \% \mathrm{Pt} / \mathrm{TiO}_{2}$ (circles). The specific surface area increased for small $\mathrm{BQDs}$, reached a maximum at $4 \mathrm{~cm}$, and decreased for larger distances. BQDs above $8 \mathrm{~cm}$ led to a comparable SSA with respect to the unquenched flame $(\infty)$. The addition of platinum has not significantly altered the SSA of the powder made at any BQD. 
than $\mathrm{BQD}=4 \mathrm{~cm}$, the temperature is rather constant by continuous droplet evaporation and combustion till BQD $=6 \mathrm{~cm}$. It is quite likely that at $\mathrm{BQD}<5 \mathrm{~cm}$ precursor was not fully consumed in the flame and TTIP oxidation may have taken place further downstream resulting in some very small particles. ${ }^{27}$

Figure 4 compares the crystal size of anatase and rutile with the average Brunauer-Emmett-Teller analysis (BET)-equivalent diameter for flames producing $5 \mathrm{wt} \%$ $\mathrm{Pt} / \mathrm{TiO}_{2}$ and quenched at different BQDs. Peak broadening in the XRD pattern (not shown) confirmed the presence of nanoscale anatase and rutile crystallites ranging from 14 to $23 \mathrm{~nm}$ and 5.0 to $11.0 \mathrm{~nm}$, respectively. The average BET-equivalent diameter lies between the anatase and rutile crystal size indicating predominantly single crystal particles consistent with TEM (Fig. 3, inset). Large crystallites for BQDs below $4 \mathrm{~cm}$ might result from particle growth by surface reaction of TTIP. ${ }^{27}$ All powders contained large fractions of anatase as seen for $\mathrm{TiO}_{2}$ made with gas-fed flames. ${ }^{12}$ Despite quenching, the anatase content remained in the range of $80-88 \mathrm{wt} \%$ regardless of the BQD distance (not shown). In contrast, gas-fed flame quenched by the critical-flow nozzle resulted in $\mathrm{TiO}_{2}$ with higher rutile content because of the reduced excess of oxygen in the nozzle. ${ }^{12}$ Nozzlequenching of gas-fed flames resulted in substoichiometric $\mathrm{TiO}_{2-x}$ showing a blue color and a fraction of rutile up to $85 \mathrm{wt} \%$. In contrast, cooling with the quenching ring here provided enough oxygen and sufficient high

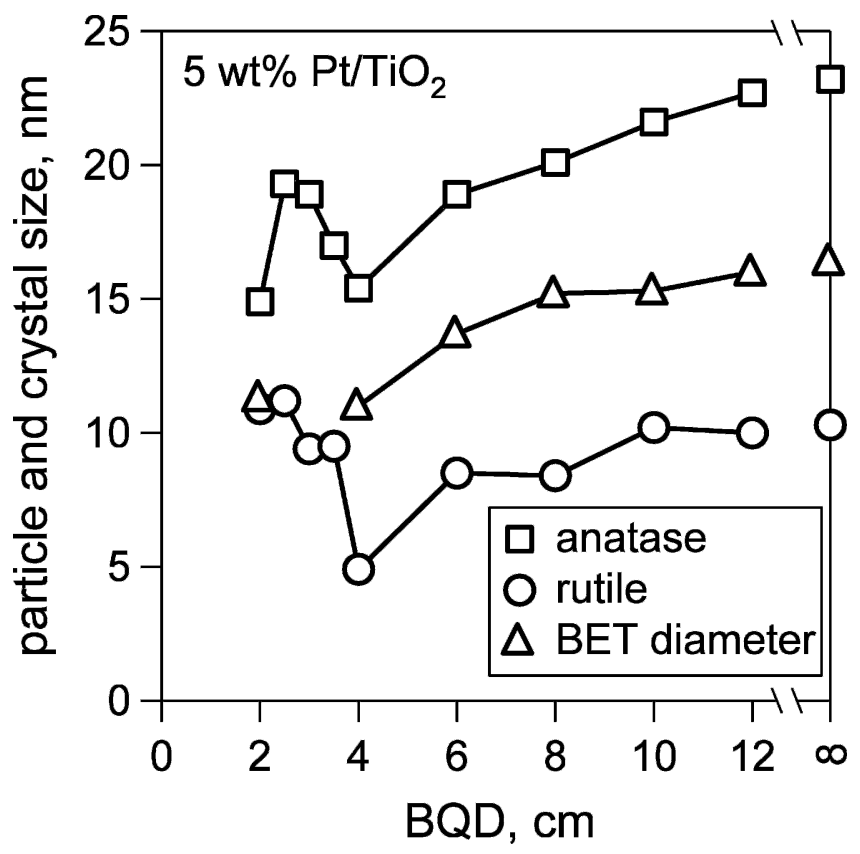

FIG. 4. $\mathrm{TiO}_{2}$ anatase (squares), rutile (circles), and BET average diameter (triangles) for $5 \mathrm{wt} \% \mathrm{Pt} / \mathrm{TiO}_{2}$ as a function of the used burner quench-ring distance (BQD). Quenching the flame below BQD = $3.5 \mathrm{~cm}$ resulted in larger crystals that may have formed by condensation of unreacted $\mathrm{TiO}_{2}$ precursor and subsequent surface growth. temperatures for the full oxidation of the titanium, so that-except for the lowest BQD—all powders appeared white without change of the crystalline composition. Only for $\mathrm{BQD}=2 \mathrm{~cm}$ the powder appeared to be slightly yellow, indicating soot or Ti-suboxides from incomplete combustion of organic matter as analyzed by temperature programmed oxidation. While the material made at $\mathrm{BQD}=2 \mathrm{~cm}$ contained $2.5 \mathrm{wt} \%$ carbon the unquenched powder had $0.6 \mathrm{wt} \%$ carbon content.

Quenching the spray flame downstream of $8 \mathrm{~cm}$ had little influence on the $\mathrm{TiO}_{2}$ particle morphology (Fig. 3), SSA (Fig. 3), and crystallinity (Fig. 4). Consequently, the primary particle growth of $\mathrm{TiO}_{2}$ must have terminated upstream, and therefore quenching above that height had little influence on the $\mathrm{TiO}_{2}$ particles. Quenching the gasfed flames at increasing burner-nozzle distances resulted in a continuous decrease of the SSA because of the increased residence time in the high temperature zone $\left(>1600{ }^{\circ} \mathrm{C}\right) .{ }^{12}$ Spray-made $\mathrm{TiO}_{2}$ particles have shorter residence times at high temperature resulting in much higher SSA at comparable production rates. ${ }^{10,12}$

Adding $\mathrm{Pt}$ to $\mathrm{TiO}_{2}$ did not affect the SSA of particles made at any BQD in the quenched and in the unquenched flame (Fig. 4). The support SSA was independent from the noble metal content also for flame-made $\mathrm{Au} / \mathrm{TiO}_{2}$, $\mathrm{Au} / \mathrm{SiO}_{2},{ }^{5} \mathrm{Pt} / \mathrm{Al}_{2} \mathrm{O}_{3},{ }^{3}$ and $\mathrm{Pd} / \mathrm{Al}_{2} \mathrm{O}_{3}{ }^{4}$

\section{Pt cluster characterization}

Figure 5 shows scanning transmission electron microscopy (STEM) images of $5 \mathrm{wt} \% \mathrm{Pt} / \mathrm{TiO}_{2}$ made without quenching at (a) high and (b) low magnification as well as quenched at BQD of (c) $2 \mathrm{~cm}$ and (d) $8 \mathrm{~cm}$. Quenching the flame at $2 \mathrm{~cm}$ resulted in an inhomogeneous bimodally sized Pt-cluster a few larger than $50 \mathrm{~nm}$ and many below $10 \mathrm{~nm}$ [Fig. 5(c)]. STEM images for powders made with $\mathrm{BQD}=4 \mathrm{~cm}$ exhibited also a bimodal Ptcluster size distribution (not shown). The maximum found Pt-cluster size was $50 \mathrm{~nm}$ compared to $200 \mathrm{~nm}$ for particles obtained with $\mathrm{BQD}=2 \mathrm{~cm}$. Quenching at $\mathrm{BQDs} \geqslant 8 \mathrm{~cm}$ led to a homogeneous Pt-cluster morphology [Fig. 5(d)] similar to the unquenched flame [Fig. 5(a)], both a few nanometers in diameter and, below the XRD detection limit, even for Pt-contents up to $10 \mathrm{wt} \%$. Energy dispersive $\mathrm{x}$-ray analysis (EDX; not shown) of all powders showed the presence of Pt beside the visible Pt-clusters (white regions). Even though the flame temperature was below the Pt-boiling point ${ }^{28}$ and Pt-pressure was supersaturated, the homogeneous particle-size distribution and the absence of large particles confirmed the gas-to-particle production route for platinum at large BQDs [Figs. 5(a), 5(b), and 5(d)]. Agglomerated noble metal particles were not found in the images [Fig. 5(b)].

The inhomogeneous particle size distribution of 


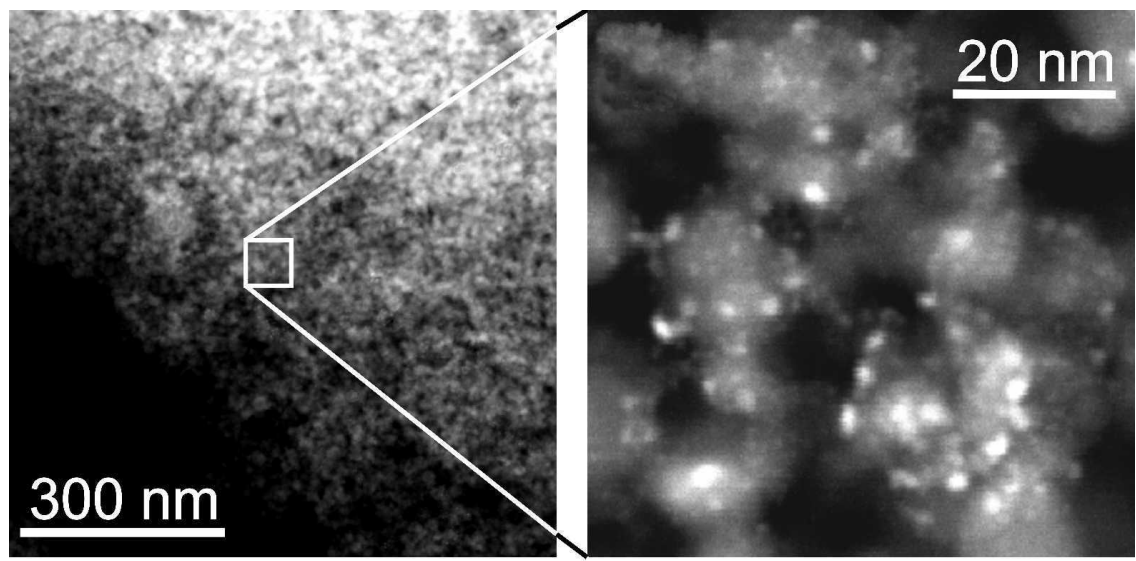

(a)

(b)
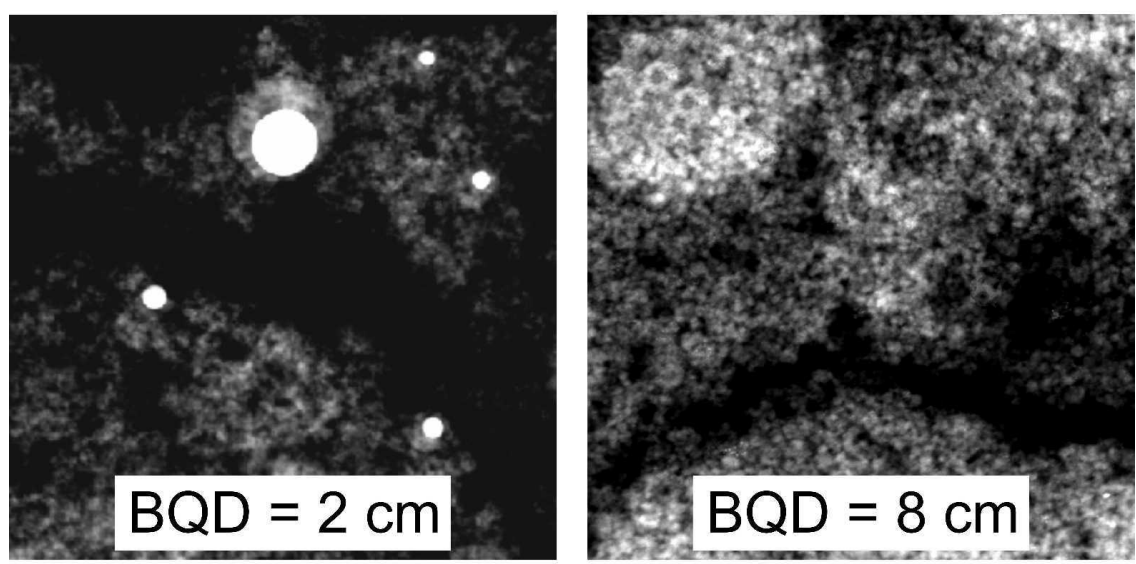

(c)

(d)

FIG. 5. $\mathrm{Pt} / \mathrm{TiO}_{2}$ particles made ( $\mathrm{a}$ and b) without quenching and quenched at $\mathrm{BQD}=(\mathrm{c}) 2 \mathrm{~cm}$ and (d) $8 \mathrm{~cm}$. The Pt clusters show bright spots on these STEM images. All images except for (b) are at the magnification of image (a). Quenching at $2 \mathrm{~cm}$ led to a bimodal Pt-cluster morphology with particle sizes of a few nanometers and above $20 \mathrm{~nm}$ (c). Not quenching (a) or quenching the flame at $8 \mathrm{~cm}$ (d) or higher resulted in Pt-clusters of homogeneous morphology. The STEM images (b-d) corroborate a Pt-cluster size of a few nanometers.

Fig. 5(c) may result from droplets that were not fully evaporated and combusted by quenching the spray flame at this low height above the burner. The temperature after quenching might not be sufficiently high for complete droplet evaporation of the Pt-precursor, which causes a part of the Pt to remain in the evaporating droplet. Therefore, the last part of platinum material is converted to large particles by what, in principle, is spray drying and thermal decomposition. Bimodal particle-size distributions have been observed for flames with low enthalpy content $^{18}$ and precursors of low thermal stability. ${ }^{29}$ Spraying pure noble metals from aqueous solutions resulted in bimodal particle size distributions because of the insufficient evaporation energy and temperature. ${ }^{30}$ Characteristic sintering times of airborne Pt-clusters at these temperatures indicate that the time in the temperature region is adequate for full coalescence. ${ }^{31}$ Typical Sauter mean droplet sizes of an equivalent spray nozzle to the one used in this study are about $10 \mu \mathrm{m}$ for ethanol as solvent. ${ }^{32}$ Nevertheless, a detailed calculation of droplet-particle dynamics is needed to resolve this, as has been done for pure $\mathrm{ZrO}_{2}$ synthesis by flame spray pyrolysis. ${ }^{33}$ A $10-\mu \mathrm{m}$ solution droplet of $1.45 \times$ $10^{-2} \mathrm{~mol} / \mathrm{l} \mathrm{Pt}$-concentration without any Pt-evaporation would result in a dense $500 \mathrm{~nm}$ Pt-cluster. For simultaneous solvent-precursor evaporation, theoretically a $650 \mathrm{~nm}$ droplet would result in the largest Pt-cluster observed in the STEM images $(\mathrm{BQD}=2 \mathrm{~cm}, 5 \mathrm{c})$ which are approximately $200 \mathrm{~nm}$. This and the decreasing maximum Pt-cluster size corroborates that the droplets, from which the large Pt-cluster comes, had partially evaporated supporting the observed bimodal Pt-cluster size distribution.

Figure 6 shows that the BQD can affect considerably the Pt-dispersion for $5 \mathrm{wt} \% \mathrm{Pt} / \mathrm{TiO}_{2}$ ranging from $40 \%$ to over $60 \%$ (filled squares). Figure 6 shows also the average Pt-cluster diameter (open symbols) obtained from the Pt-dispersion data for $2.5 \mathrm{wt} \%$ (circles) and $5 \mathrm{wt} \%$ (squares). The Pt-dispersion exhibited a maximum of about $63 \%$ at $8 \mathrm{~cm}$ BQD. At $12 \mathrm{~cm} \mathrm{BQD}$, the Ptdispersion was equivalent to that of the unquenched flame $(\mathrm{BQD}=\infty)$, indicating that Pt-cluster growth has 


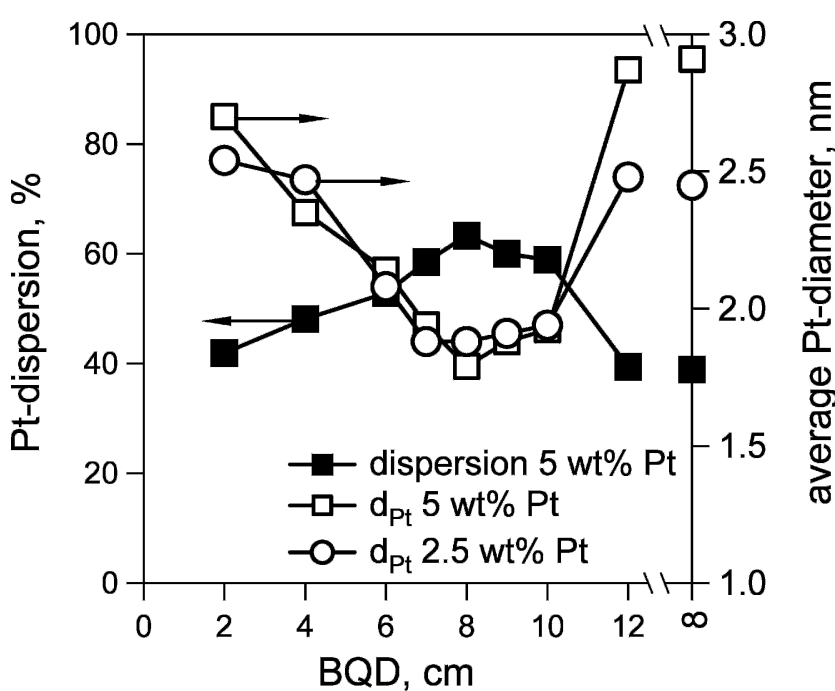

FIG. 6. Pt-dispersion (filled squares) and Pt-clusters size (open symbols) as a function of burner quench ring distance (BQD) for $\mathrm{Pt} / \mathrm{TiO}_{2}$ content $2.5 \mathrm{wt} \%$ (circles) and $5 \mathrm{wt} \% \mathrm{Pt}$ (squares) made by flame spray pyrolysis of precursor sprays. Quenching at $8 \mathrm{~cm}$ led to the highest $\mathrm{Pt}$ dispersion and therefore the smallest average Pt diameter. The average Pt-cluster diameter was inferred from the Pt dispersion.

stopped at about $12 \mathrm{~cm}$ BQD $\left(1000{ }^{\circ} \mathrm{C}\right.$ unquenched flame). A low Pt-dispersion resulted from the bimodal Pt-cluster size distribution at small BQDs. Large Pt clusters [e.g., $50 \mathrm{~nm}$, Fig. 5(c)] contain a considerable fraction of Pt that was not accessible for $\mathrm{CO}$ chemisorption, thereby decreasing the overall Pt-dispersion. With increasing quenching height, precursor droplets fully evaporate, releasing platinum in the gas-phase. Increasing the BQD above $8 \mathrm{~cm}$ led to a decrease of the Pt-dispersion. This can be attributed to a slower cooling of Pt-vapor and lower supersaturation that favors nucleation of fewer and larger particles on the surface of the $\mathrm{TiO}_{2}$ by either gas-to-particle conversion or by surface diffusion and rearrangement.

Therefore, quenching at $8 \mathrm{~cm}$ led to the smallest $\mathrm{Pt}$ clusters of 1.8-nm diameter. Precursor droplets have evaporated fully at this height (Fig. 1) and homogeneous or heterogeneous nucleation was enhanced by the high cooling rate of the quench ring that resulted in higher supersaturation. In contrast to the XRD and the STEM analysis, for which the Pt-clusters were too small for quantitative evaluation, the $\mathrm{CO}$-chemisorption results confirm the influence of the quenching on the average Pt-cluster size. A minimum of Pt-cluster size at BQD = $8 \mathrm{~cm}$ was found also when $\mathrm{Pt} / \mathrm{TiO}_{2}$ was made with $2.5 \mathrm{wt} \%$ Pt-content (Fig. 6, circles). For smaller BQDs the average Pt-cluster size is independent of Pt content, resulting in similar particle sizes for $2.5 \mathrm{wt} \%$ and $5 \mathrm{wt} \%$ Pt-content. This indicates that the temperature history of the aerosol determines its size characteristics rather than the Pt-content suggesting heterogeneous Pt-cluster formation on $\mathrm{TiO}_{2}$.
Figure 7 shows that increasing the quench gas flow rate decreases the average Pt-cluster size at $\mathrm{BQD}=$ $8 \mathrm{~cm}$. The higher the quench gas flow rate was, the higher the cooling rate leading to a higher supersaturation of platinum in the flame and to a decrease of its surface mobility on the $\mathrm{TiO}_{2}$ support. This effect, however, is limited up to about $30 \mathrm{l} / \mathrm{min}$ and flow rates above $30 \mathrm{l} / \mathrm{min}$ did not further reduce the Pt-diameter. As expected from Figs. 3 and 4, the $\mathrm{TiO}_{2}$ characteristics are not affected by increasing the quench gas flow rate 0 $50 \mathrm{l} / \mathrm{min}$ at this BQD. The Pt-cluster size can be controlled from 1.8 to $3.0 \mathrm{~nm}$ by the quench gas flow at this BQD independent of that of the $\mathrm{TiO}_{2}$ support. This was achieved by the judicious placement of the quench ring at a BQD where the formation of the substrate $\mathrm{TiO}_{2}$ had been completed.

Figure 8 compares the increase in Pt diameter with increasing Pt-content (1-10 wt\%) for the unquenched (squares) and quenched spray flame $\left(40 \mathrm{l} / \mathrm{min} \mathrm{O}_{2}\right.$, $\mathrm{BQD}=8 \mathrm{~cm}$, circles). For the unquenched flame, the Pt-cluster size increased from 1.7 to $3.3 \mathrm{~nm}$ for $1-10 \mathrm{wt} \%$ Pt. For the quenched flame, the Pt-cluster size increased from 1.7 to $2.3 \mathrm{~nm}$ over the same increase in Pt content. For the latter flame, the Pt sizes were drastically reduced for all contents larger than $1 \mathrm{wt} \%$ resulting in excellent $\mathrm{Pt}$ dispersion at these high Pt contents. The increase in the noble metal particle size with its precursor concentration is consistent for many flame-made noble metal/ceramic

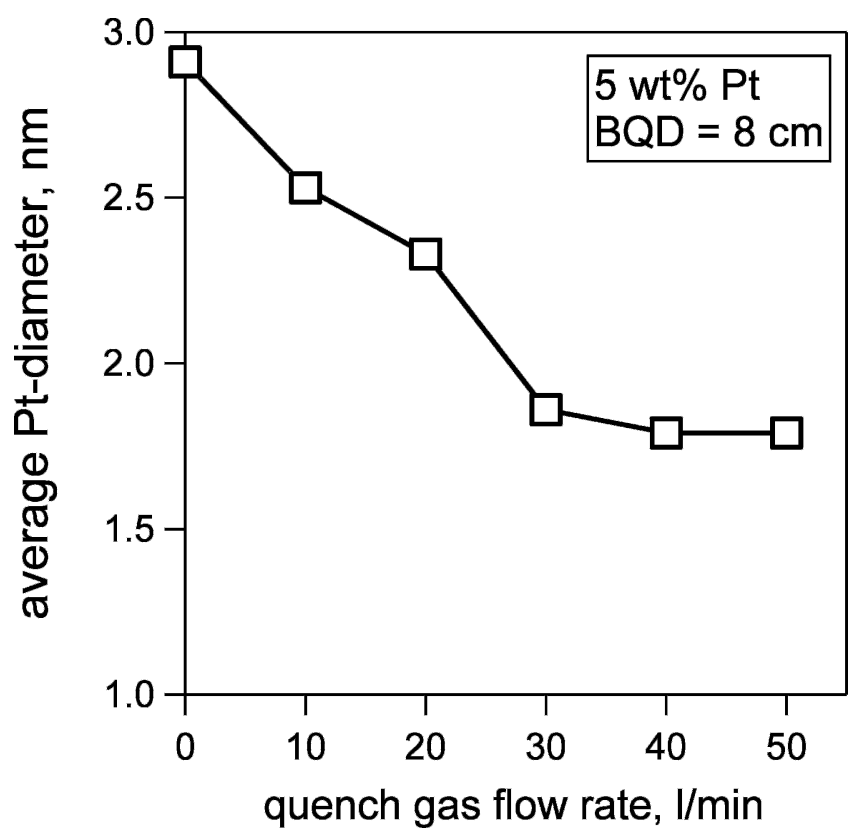

FIG. 7. The Pt-cluster size as a function of the quench gas flow rate for synthesis of $5 \mathrm{wt} \% \mathrm{Pt} / \mathrm{TiO}_{2}$ in a spray flame quenched at a burner quench-ring distance of $8 \mathrm{~cm}$. Increasing the quench gas flow rate up to $30 \mathrm{l} / \mathrm{min}$ led to a decrease of the average Pt-diameter. The higher the quench gas flow rate was, the higher the cooling rate leading to a higher supersaturation of platinum in the flame and to a possible decrease of its surface mobility on the $\mathrm{TiO}_{2}$ support. 
$\mathrm{H}$. Schulz et al.: Independent control of metal cluster and ceramic particle characteristics during one-step synthesis of $\mathrm{Pt} / \mathrm{TiO}{ }_{2}$

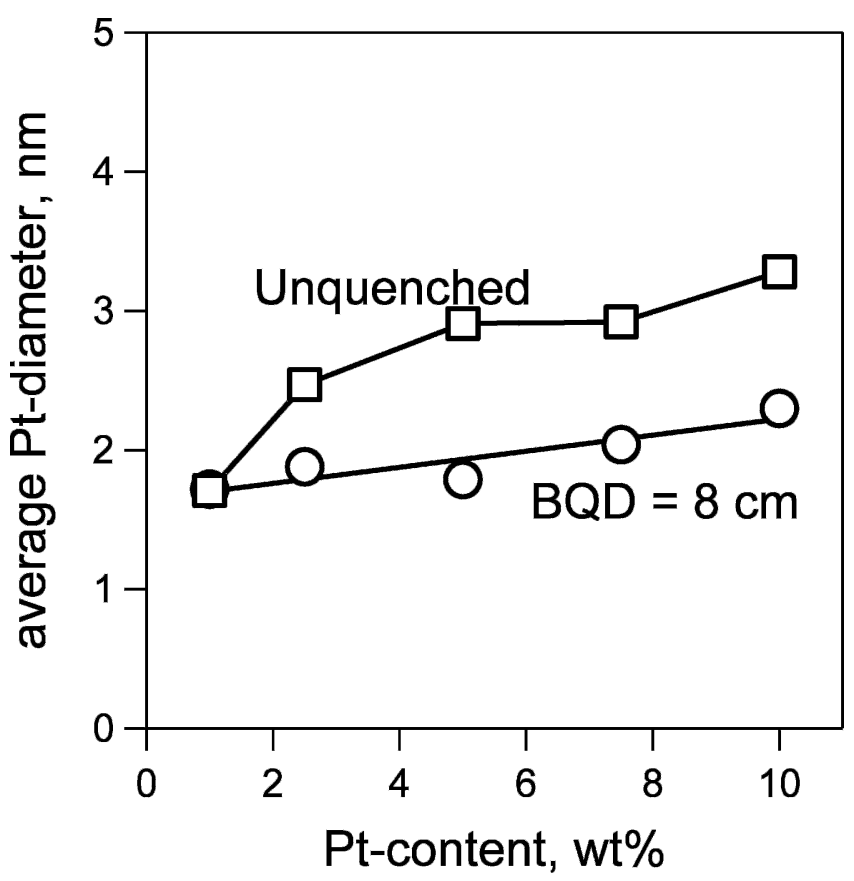

FIG. 8. Increasing the Pt content resulted in an increase of the average Pt-cluster diameter for the quenched (40 1/min) and the unquenched flame. The average Pt-cluster size increased with the Pt content under both conditions. Producing Pt clusters at unquenched conditions resulted in Pt clusters larger than those for quenched flame or Ptcontents higher than $1 \mathrm{wt} \%$.

composites. ${ }^{3,5,6,34}$ At the same time, note that the SSA of $\mathrm{TiO}_{2}$ made in both flames was rather constant (90$100 \mathrm{~m}^{2} / \mathrm{g}$; Fig. 3). For $1 \mathrm{wt} \%$ Pt-content, $66 \%(1.7 \mathrm{~nm})$ of the total $\mathrm{Pt}$ are available for chemisorption regardless of quench gas as probably the Pt clusters are too small and near their critical size. For comparison, full accessibility is achieved theoretically for approximately $1.1 \mathrm{~nm}$ Pt clusters when every Pt atom is on the surface, assuming no blocking by the contact with the $\mathrm{TiO}_{2}$ surface.

\section{Platinum cluster formation}

$\mathrm{TiO}_{2}$ particles and Pt clusters stop growing in different regions of the flame as observed for $\mathrm{Au} / \mathrm{TiO}_{2}$ composite. ${ }^{5}$ Titania particles are probably formed first, then platinum forms on these particles. In addition, the encapsulation of Pt clusters in the $\mathrm{TiO}_{2}$ matrix is very unlikely for such a high dispersion that can be qualitatively confirmed by STEM analysis. The reason for obtaining such a high Pt dispersion for high Pt contents includes different physical mechanisms. Pt-clusters might be nested at steps and kinks on the highly stepped surface of the $\mathrm{TiO}_{2}$ particles that offer many of these preferred nucleation sites. Platinum was supersaturated in the flame, and $\mathrm{Pt}$ clusters were formed by homo- or heterogeneous nucleation upon cooling. Partial oxidation of the platinum resulting in the formation of $\mathrm{PtO}$ might additionally reduce the mobility on the $\mathrm{TiO}_{2}$ surface. ${ }^{35}$ The average Pt cluster size made by both unquenched and quenched (Fig. 8; $\mathrm{BQD}=8 \mathrm{~cm}$ ) flames was slightly above the average particle size, $d_{\mathrm{Pt}}=1.7 \mathrm{~nm}$ (at $20 \%$ of Pt-monolayer), observed for $\mathrm{Pt}$ clusters made in ultra high vacuum (UHV) on anatase. ${ }^{36}$ The $1-10 \mathrm{wt} \%$ Pt-content corresponded to $2-20 \%$ of a Pt-monolayer on top of $\mathrm{TiO}_{2}$. For these monolayer fractions, an almost linear increase of the average noble metal particle diameter on $\mathrm{TiO}_{2}$ surfaces has been observed in $\mathrm{UHV},{ }^{37}$ similar to Fig. 8. Platinum and $\mathrm{TiO}_{2}$ exhibit strong metal-support interaction (SMSI) that influences CO-adsorption. ${ }^{38}$ The consistency of the two methods, STEM images and COchemisorption, for the Pt-cluster diameter determination indicated that the SMSI effect, which decreases the chemisorption of $\mathrm{CO}$, may not be that significant.

Changing the production conditions such as dispersion gas flow, liquid flow, or concentration will alter not only the noble metal particle size but also the support properties such as particle size ${ }^{3}$ and thermal stability. ${ }^{39}$ For noble metals forming oxides on the ceramic support in the flame, the quench ring can lead to enhanced noble metal dispersion. Therefore, an independent particle size control of ceramic support and noble metal particles is possible by efficient quench cooling of the flame spray process without other changes in production conditions that can give undesired change on the support particle crystallinity of specific surface area.

\section{SUMMARY AND CONCLUSIONS}

A simple and easy-to-operate radial quench cooling method was successfully applied in one-step flame spray synthesis of $\mathrm{Pt} / \mathrm{TiO}_{2}$ particles. This results in closely and independently controlled Pt-dispersion without changing the $\mathrm{TiO}_{2}$ substrate properties. The particle size of the supporting ceramic $\left(\mathrm{TiO}_{2}\right)$ can be controlled by the standard flame spray pyrolysis parameters such as precursor, composition, concentration, liquid feed rate, and oxidant dispersion gas flow rate, while the particle size of the expensive noble metal $(\mathrm{Pt})$ can be controlled by rapid quenching at various heights and cooling rates. Inhomogeneously sized noble metal particles were obtained when the residence time upstream of the quenching level was insufficient for complete droplet evaporation. This resulted in a change of the particle formation mechanism from one-droplet-to-gas-to-particles to one-droplet-toone-particle. However, quenching the flame after complete droplet evaporation resulted in well-dispersed Pt-clusters on the $\mathrm{TiO}_{2}$ surface.

For high Pt contents (10 wt\%) the average Pt cluster size was significantly reduced by $30 \%$, i.e., from 3.3 to $2.3 \mathrm{~nm}$, by quenching. In contrast, the $\mathrm{TiO}_{2}$ support properties such as SSA, morphology, and crystal structure were not significantly influenced by quenching at this 
position in the flame zone. It has been shown that radial quenching at various axial positions gives direct control of the noble metal size independently of the properties of the ceramic support. This enables the production of tailor-made noble metal particle sizes at any noble metal content coupled with thermally stable, nano-sized ceramic supports suitable for applications such as catalysts or sensors. A maximum Pt-dispersion was obtained by quenching at the position of complete droplet evaporation. This dispersion corresponds to Pt-cluster sizes that are usually obtained by costly and complex ultrahigh vacuum processes. As a conclusion, the combination of radial quench cooling and flame spray synthesis is an efficient and simple method of producing complex materials of desired properties, which normally require numerous process steps by using conventional synthesis methods such as ultrahigh vacuum processes, impregnation, or precipitation. This has direct implication on catalyst and sensor manufacture and performance.

\section{ACKNOWLEDGMENT}

We thank Dr. F. Krumeich for the TEM, EDX, and STEM analysis.

\section{REFERENCES}

1. C.J.H. Jacobsen, S. Dahl, P.L. Hansen, E. Tornqvist, L. Jensen, H. Topsoe, D.V. Prip, P.B. Moenshaug, and I. Chorkendorff: Structure sensitivity of supported ruthenium catalysts for ammonia synthesis. J. Mol. Catal. Chem. 163, 19 (2000).

2. L. Mädler, T. Sahm, A. Gurlo, J-D. Grunwaldt, N. Barsan, W.U., and S.E. Pratsinis: Sensing low concentrations of CO using flamespray-made $\mathrm{Pt} / \mathrm{SnO}_{2}$ nanoparticles. J. Nanoparticle Res. (2005, submitted).

3. R. Strobel, W.J. Stark, L. Mädler, S.E. Pratsinis, and A. Baiker: Flame-made platinum/alumina: Structural properties and catalytic behaviour in enantioselective hydrogenation. J. Catal. 213, 296 (2003).

4. R. Strobel, F. Krumeich, W.J. Stark, S.E. Pratsinis, and A. Baiker: Flame spray synthesis of $\mathrm{Pd} / \mathrm{Al}_{2} \mathrm{O}_{3}$ catalysts and their behavior in enantioselective hydrogenation. J. Catal. 222, 307 (2004).

5. L. Mädler, W.J. Stark, and S.E. Pratsinis: Simultaneous deposition of $\mathrm{Au}$ nanoparticles during flame synthesis of $\mathrm{TiO}_{2}$ and $\mathrm{SiO}_{2}$. J. Mater. Res. 18, 115 (2003).

6. T. Johannessen and S. Koutsopoulos: One-step flame synthesis of an active $\mathrm{Pt} / \mathrm{TiO}_{2}$ catalyst for $\mathrm{SO}_{2}$ oxidation-A possible alternative to traditional methods for parallel screening. J. Catal. 205. 404 (2002).

7. U. Backman, U. Tapper, and J.K. Jokiniemi: An aerosol method to synthesize supported metal catalyst nanoparticles. Synth. Metals 142, 169 (2004).

8. R. Mueller, H.K. Kammler, S.E. Pratsinis, A. Vital, G. Beaucage, and P. Burtscher: Non-agglomerated dry silica nanoparticles. Powder Technol. 140, 40 (2004).

9. S.E. Pratsinis, W.H. Zhu, and S. Vemury: The role of gas mixing in flame synthesis of titania powders. Powder Technol. 86, 87 (1996).

10. H.K. Kammler, R. Jossen, P.W. Morrison, S.E. Pratsinis, and
G. Beaucage: The effect of external electric fields during flame synthesis of titania. Powder Technol. 135, 310 (2003).

11. S. Vemury and S.E. Pratsinis: Corona-assisted flame synthesis of ultrafine titania particles. Appl. Phys. Lett. 66, 3275 (1995).

12. K. Wegner and S.E. Pratsinis: Nozzle-quenching process for controlled flame synthesis of titania nanoparticles. AIChE J. 49, 1667 (2003).

13. J.P. Hansen, J.R. Jensen, H. Livbjerg, and T. Johannessen: Synthesis of $\mathrm{ZnO}$ particles in a quench-cooled flame reactor. AIChE J. 47, 2413 (2001).

14. T. Johannessen, J.R. Jenson, M. Mosleh, J. Johansen, U. Quaade, and H. Livbjerg: Flame synthesis of nanoparticles-Applications in catalysis and product/process engineering. Chem. Eng. Res. Des. 82, 1444 (2004).

15. G.R. Bamwenda, S. Tsubota, T. Nakamura, and M. Haruta: Photoassisted hydrogen-production from a water-ethanol solution-A comparison of activities of $\mathrm{Au}-\mathrm{TiO}_{2}$ and $\mathrm{Pt}-\mathrm{TiO}_{2}$. J. Photochem. Photobio., A Chem. 89, 177 (1995).

16. X.X. Han, R.X. Zhou, G.H. Lai, and X.M. Zheng: Influence of support and transition metal $(\mathrm{Cr}, \mathrm{Mn}, \mathrm{Fe}, \mathrm{Co}, \mathrm{Ni}$ and $\mathrm{Cu})$ on the hydrogenation of p-chloronitrobenzene over supported platinum catalysts. Catal. Today 93-95, 433 (2004).

17. L. Mädler, H.K. Kammler, R. Mueller, and S.E. Pratsinis: Controlled synthesis of nanostructured particles by flame spray pyrolysis. J. Aerosol Sci. 33, 369 (2002).

18. R. Jossen, S.E. Pratsinis, W.J. Stark, and L. Mädler: Criteria for flame spray synthesis of hollow, shell-like or inhomogeneous oxides. J. Am. Ceram. Soc. 88, 1388 (2005).

19. P.W. Morrison, R. Raghavan, A.J. Timpone, C.P. Artelt, and S.E. Pratsinis: In situ Fourier transform infrared characterization of the effect of electrical fields on the flame synthesis of $\mathrm{TiO}_{2}$ particles. Chem. Mater. 9, 2702 (1997).

20. H.K. Kammler, S.E. Pratsinis, P.W. Morrison, and B. Hemmerling: Flame, temperature measurements during electrically assisted aerosol synthesis of nanoparticles. Combust. Flame 128, 369 (2002).

21. C.J. Howard, T.M. Sabine, and F. Dickson: Structural and thermal parameters for rutile and anatase. Acta Crystallographica Section B Structural Science 47, 462 (1991).

22. H. Seki, N. Ishizawa, N. Mizutani, and M. Kato: High temperature structures of the rutile-type oxides, $\mathrm{TiO}_{2}$ and $\mathrm{SnO}_{2}$. Yogyo Kyokai Shi. J. Ceramic Assoc. of Japan 92, 219 (1984).

23. J.M. Garcia-Cortes, J. Perez-Ramirez, J.N. Rouzaud, A.R. Vaccaro, M.J. Illan-Gomez, and C.S.M. de Lecea: On the structure sensitivity of deNO $(x)$ HC-SCR over Pt-beta catalysts. J. Catal. 218. $111(2003)$

24. P.B. Wells: Characterization of the standard platinum silica catalyst Europt-1.5. chemisorption of carbon-monoxide and of oxygen. Appl. Catal. 18, 259 (1985).

25. N.A. Chigier and C.G. McCreath: Combustion of droplets in sprays. Acta Astronaut. 1, 687 (1974).

26. S.H. Oh, D.I. Kim, and M.S. Paek: Experiments on air-assist spray and spray flames. Atom. Sprays 11, 775 (2001).

27. K. Nakaso, K. Okuyama, M. Shimada, and S.E. Pratsinis: Effect of reaction temperature on CVD-made $\mathrm{TiO}_{2}$ primary particle diameter. Chem. Eng. Sci. 58, 3327 (2003).

28. N.I.S.T. Chemistry, WebBook, National Institute of Standards and Technology, http://webbook.nist.gov/chemistry/ (2003).

29. L. Mädler and S.E. Pratsinis: Bismuth oxide nanoparticles by flame spray pyrolysis. J. Am. Ceram. Soc. 85, 1713 (2002).

30. H. Keskinen, J.M. Makela, M. Vippola, M. Nurminen, J. Liimatainen, T. Lepisto, and J. Keskinen: Generation of silver/ palladium nanoparticles by liquid flame spray. J. Mater. Res. 19. 1544 (2004).

31. A. Seipenbusch, A.P. Weber, A. Schiel, and G. Kasper: Influence 
$\mathrm{H}$. Schulz et al.: Independent control of metal cluster and ceramic particle characteristics during one-step synthesis of $\mathrm{Pt} / \mathrm{TiO}{ }_{2}$

of the gas atmosphere on restructuring and sintering kinetics of nickel and platinum aerosol nanoparticle agglomerates. J. Aerosol Sci. 34, 1699 (2003).

32. L. Mädler, H.K. Kammler, R. Mueller, and S.E. Pratsinis: Controlled synthesis of nanostructured particles by flame spray pyrolysis. J. Aerosol Sci. 33, 369 (2002).

33. M.C. Heine and S.E. Pratsinis: Droplet and particle dynamics during flame spray synthesis of nanoparticles. Ind. Eng. Chem. Res. 44, 6222 (2005).

34. W.Y. Teoh, L. Mädler, D. Beydoun, S.E. Pratsinis, and A. Amal: Direct (one-step) synthesis for $\mathrm{TiO}_{2}$ and $\mathrm{Pt} / \mathrm{TiO}_{2}$ nanoparticles for photocatalytic mineralization of sucrose. Chem. Eng. Sci. 60,5852 (2005).

35. J.D. Grunwaldt and A. Baiker: Axial variation of the oxidation state of Pt- $\mathrm{Rh} / \mathrm{Al}_{2} \mathrm{O}_{3}$ during partial methane oxidation in a fixedbed reactor: An in situ X-ray absorption spectroscopy study. Catal. Lett. 99, 5 (2005).

36. S. Gan, A. El-Azab, and Y. Liang: Formation and diffusion of $\mathrm{Pt}$ nanoclusters on highly corrugated anatase $\mathrm{TiO}_{2}(001)-(1 \times 4)$ surface. Surf. Sci. 479, L369 (2001).

37. D.A. Chen, M.C. Bartelt, S.M. Seutter, and K.F. McCarty: Small, uniform, and thermally stable silver particles on $\mathrm{TiO}_{\mathrm{s}}(110)-(1 \times$ 1). Surf. Sci. 464, L708 (2000).

38. S.J. Tauster: Strong metal-support interactions. Acc. Chem. Res. 20, 389 (1987).

39. L. Mädler, W.J. Stark, and S.E. Pratsinis: Flame-made ceria nanoparticles. J. Mater. Res. 17, 1356 (2002). 